\title{
Pathogenic mechanisms of deregulated microRNA expression in thyroid carcinomas of follicular origin
}

\author{
Juliane Braun, Stefan Hüttelmaier ${ }^{*}$
}

\begin{abstract}
Thyroid cancer is one of the most common malignancies of the endocrine system with increasing incidence. The vast majority of thyroid carcinomas derive from thyroid hormone producing follicular cells. Carcinomas of follicular origin are classified as follicular (FTCs), papillary (PTCs), partially differentiated (PDTCs) or anaplastic (ATCs) thyroid carcinomas. While FTCs and PTCs can be managed effectively, ATCs are considered one of the most lethal human cancers. Despite the identification of various genetic alterations, pathogenic mechanisms promoting the progression of thyroid carcinomas are still largely elusive. Over the recent years, aberrant microRNA expression was revealed in all as yet analyzed human cancers, including thyroid carcinomas. In view of the rapidly evolving perception that deregulated microRNA expression serves a pivotal role in tumor progression, microRNAs provide powerful tools for the diagnosis of thyroid carcinomas as well as the identification of potential therapeutic targets. Here, we summarize recent findings on microRNA signatures in thyroid carcinomas of follicular origin and discuss how deregulated microRNA expression could promote cancer progression.
\end{abstract}

\section{Introduction}

Thyroid carcinomas represent the most common cancer of the endocrine system [1]. More than 95\% of these carcinomas originate from follicular thyroid cells, whereas only $3 \%$ are of $\mathrm{C}$-cell origin, referred to as medullary thyroid carcinomas (MTCs) [2]. The most frequent follicular tumors are benign hyperplastic adenomas (FTAs), whereas papillary thyroid carcinomas (PTCs) are the most frequent thyroid carcinoma (approximately 90\%) [3]. PTCs are composed of welldifferentiated epithelial cells and can be distinguished by visible changes in nuclear morphology and appearance [4]. Follicular thyroid carcinomas (FTCs) with a prevalence of less than $10 \%$ are morphological similar to FTAs but capable of vascular invasion [2]. Although some of these well-differentiated carcinomas behave aggressively, the vast majority of PTCs and FTCs can be managed effectively. In contrast, the rare (2-7\%) undifferentiated, anaplastic thyroid carcinomas (ATCs)

\footnotetext{
* Correspondence: stefan.huettelmaier@medizin.uni-halle.de

Institute of Molecular Medicine, Section for Molecular Cell Biology, Martin Luther University of Halle-Wittenberg, ZAMED Heinrich-Damerow-Str.1, 06120 Halle, Germany

Full list of author information is available at the end of the article
}

behave very aggressively, rapidly invade adjacent tissues and are thus considered one of the most lethal human cancers [2]. At present there is no effective treatment of ATCs and death usually occurs within six months after diagnosis [5]. ATCs are characterized by partially or completely undifferentiated cells with a high mitosis rate, necrotic areas, spindle-like cell morphologies as well as giant and occasionally squamous cells $[5,6]$. Poorly differentiated thyroid carcinomas (PDTCs) present an 'intermediate' entity. They appear partially dedifferentiated compared to FTCs or PTCs and typically behave more aggressively [5]. Several of these tumors arise de novo, whereas others seem to originate from PTCs or FTCs [7].

Thyroid tumors are supposed to be mainly monoclonal malignancies arising based on somatic mutations of progenitor cells. Putative risk factors for genomic instabilities are radiation exposure, active oxygen-species $\left(\mathrm{H}_{2} \mathrm{O}_{2}\right.$ is necessary for thyroid hormone synthesis) and estrogen. Historical events exhibit radiation exposure as the major risk for PTCs, since atomic bomb survivors and Chernobyl victims frequently developed these tumors [8]. One of the major risks for FTCs is dietary iodine deficiency resulting in thyroid proliferation
C Biomed Central

๑ 2011 Braun and Hüttelmaier; licensee BioMed Central Ltd. This is an open access article distributed under the terms of the Creative Commons Attribution License (http://creativecommons.org/licenses/by/2.0), which permits unrestricted use, distribution, and reproduction in any medium, provided the original work is properly cited. 
(endemic goiter) as a compensatory mechanism [9]. Genetic predisposition associated thyroid cancers are known for familial polyposis coli (mutations in APC), Cowden disease (mutations in PTEN) and Werner syndrome (mutations in WRN) [2]. Moreover, two sequence variants of loci 9q22.33 and 14q13.3 were found to be associated with a higher risk of FTCs and PTCs [10].

Genetic alterations in oncogenes that are involved in the activation of cell signalling pathways have been observed in the vast majority of malignant thyroid carcinomas. Mutation of the BRAF gene is most prominent in PTCs with an appearance up to $50 \%[2,11,12]$. One major gain-of-function mutation of BRAF, a substitution of valine to glutamate at position 600 (V600E), results in constitutive activation of the MAPK pathway $[13,14]$. RAS gene (KRAS, HRAS, NRAS) mutations instead were found in all thyroid cancers: FTAs (frequency: 2040\%), FTCs (frequency: 40-50\%), PDTCs (frequency: 2055\%) and ATCs (frequency: 20-60\%) [2,11,12]. Activation of the G-protein RAS stimulates MAPK and other signalling pathways like PI3K/AKT. Less frequent are RET rearrangements (20-40\% in PTCs, $\sim 10 \%$ in PDTCs) due to inter-chromosomal translocations. In ATCs and PDTCs, CTNNB1 (0-25\% in PDTCs, 66\% in ATCs) and TP53 mutations (20-38\% in PDTCs; $67-88 \%$ in ATCs) were observed $[2,11,12,15,16]$. NTRK1 rearrangements were exclusively identified in PTCs $(\sim 10 \%)$. The protooncogene NTRK1 (also known as TRK) encodes a transmembrane tyrosine-kinase receptor for nerve growth factor and activates ERK, PI3K and phospholipase $\gamma$ $(\mathrm{PLC} \gamma)$ signalling pathways. Notably, all mutations in PTCs are nearly 100\% exclusive. Rearrangements leading to the chimeric protein PAX8-PPAR $\gamma$ were only identified in FTCs (35\%) and FTAs (2-10\%) [2,3,11]. Additionally, AKT signalling appears most accelerated in ATCs and PTCs due to PTEN mutations and/or PIK3CA amplification [17]. Together the frequency preference of genetic alterations observed in distinct thyroid cancers as well as the observation that well-differentiated thyroid carcinomas precede or co-exist with PDTCs or ATCs supports the view that most undifferentiated thyroid carcinomas evolve by sequential progression (reviewed in: [2]).

In addition to genetic alterations, recent studies indicate that thyroid carcinomas like the majority of as yet analyzed tumors are characterized by aberrant expression of microRNAs (miRNAs). These small, non-coding RNAs of 20-24 nucleotides in length are evolutionarily conserved and control gene expression at the post-transcriptional level [18]. At present, 1366 mature human microRNAs are listed in miR-Base (mirbase.org, release 16). The vast majority of identified and characterized microRNAs target the 3'-untranslated region (3' UTR) of mRNAs and modulate target transcript degradation, translation or both $[19,20]$. Two classes of microRNAs relevant to cancer are distinguished: 'onco-miRs' with tumor promoting effects versus 'tumor-suppressive' microRNAs that antagonize cancer progression. In the past years, several studies identified miRNA signatures in thyroid carcinomas aiming to reveal how they modulate thyroid cancer progression and to evaluate their potential for thyroid cancer diagnosis.

\section{MicroRNA signatures in follicular thyroid carcinomas (FTCs)}

Malignant FTCs and benign FTAs share significant similarities at the morphological and molecular level and thus microRNAs could serve as valuable markers to distinguish these tumors. The first study addressing this aspect on the basis of a limited set of human microRNAs (235 distinct human microRNAs) revealed four microRNAs (miR-346, -328, -192, -197) moderately upregulated by 1.34-1.82 fold in FTCs when compared to FTAs [21]. The authors claimed this moderate upregulation sufficed to distinguish FTAs from FTCs in 74\% of analyzed patient samples (23 FTCs, 20 FTAs). In vitro, the upregulation of miR-197 and -346 was associated with elevated proliferation of HEK293T and two FTC-derived cell lines. This pro-proliferative effect was suggested to correlate with miR-controlled expression of ACVR1 (activin A receptor type 1), TSPAN3 (tetraspanin 3), CFLAR (Caspase 8 and FADD-like apoptosis regulator) and EFEMP2 (fibulin 4), although no direct regulation of these targets by miR-197 or -346 was demonstrated [21]. The abundance of these mRNAs was decreased in the majority of analyzed FTCs and was proposed to distinguish FTAs from FTCs [21]. Notably, previous studies suggested activin signalling to act on growth inhibition of FTC-derived cells in vitro, but miRNA-mediated regulation of Activin signalling remains to be shown [22]. TSPAN3 was inversely correlated with the metastatic potential in melanoma and the extracellular matrix (ECM) component EFEMP2 was reported to be over expressed in colon carcinomas but decreased in prostate cancer [23-25].

In comprehensive studies aiming at the identification of microRNA signatures distinguishing thyroid carcinomas from non-transformed thyroid tissue (NT), Nikiforova and colleagues [26] could not confirm the results of Weber et al. [21], except for miR-197. This miRNA showed a higher expression in oncocytic FTCs compared to NTs, whereas expression appeared largely unaffected in conventional FTCs $[21,26]$. Notably, miR-328 expression, previously suggested being higher in FTCs than in FTAs, was found to be upregulated in FTAs but not in FTCs by Nikiforova et al [26]. The increased expression of miR-221/-222 appears to be a hallmark of 
thyroid cancers of follicular origin, since both miRNAs were found to be expressed at high levels in FTCs, PTCs, PDTCs and ATCs [26-31] (Figure 1). Accordingly, their expression was largely unaffected in FTAs, hyperplastic nodules and medullary thyroid carcinomas (MTCs) [26]. Compared to non-transformed 'normal' thyroid (NT) and hyperplastic nodules four additional miRNAs were significantly increased in conventional FTCs (miR-187, -224, $-155,-146 \mathrm{~b})$ as well as in oncocytic FTCs (miR-187, -339, -183, -197). MiR-187 is one of the ten most upregulated microRNAs in PTCs, FTCs and PDTCs but apparently remains unaffected in FTAs. This suggests miR-187 as a useful marker for distinguishing FTCs from FTAs that however is not suitable for discriminating FTCs from other carcinomas of follicular origin. The only few studies addressing miRNA signatures in FTCs focused exclusively on the upregulation of microRNAs. However, by comparing ATC samples with NTs, FTCs and PTCs, we observed a significant reduction in miR-26a/-b and let-7g expression in FTCs. These miRNAs are considered tumor suppressive miRNAs [32-35].

In conclusion, comprehensive miRNA signature analyses in FTCs, in particular with respect to distinct subtypes like oncocytic versus conventional FTCs, are still lacking. Thus, it remains largely elusive if FTCs can be distinguished from other thyroid carcinomas or FTAs by altered miRNA expression profiles at this point.

\section{MicroRNA signatures in papillary thyroid carcinomas (PTCs)}

The upregulation of the miR-221/-222 cluster and miR181 is the most consistent finding in all studies addressing miRNA signatures in PTCs $[26,27,31,36,37]$. Moreover, increased expression of miR-146b, $-155,-21$ and -220 was

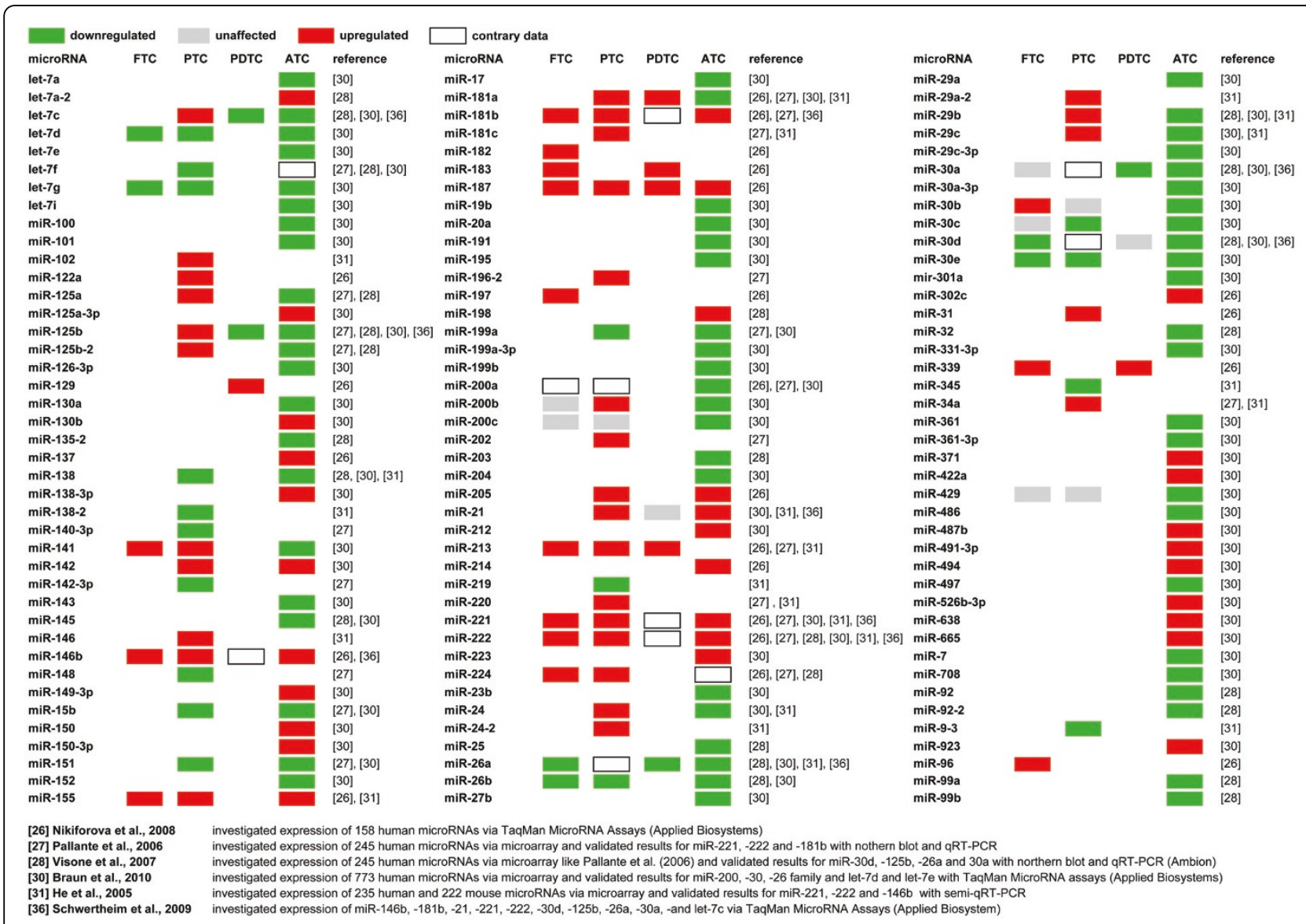

Figure 1 Deregulated miRNA expression in thyroid carcinomas of follicular origin in comparison to normal thyroid tissue. Altered expression of miRNAs observed by indicated studies is represented by color coding. Deregulated expression was classified as up- (red), unaffected (grey) or downregulated (green) in comparison to non-transformed thyroid tissue based on individual studies. Contradictory data are indicated by boxes. The presented data base on different thresholds, were quantified using distinct methods and more importantly distinct miRNA sets. Thus, the presented summary of observed miRNA signatures remains incomplete, preliminary and requires substantial further validation. This is particularly important for FTCs and PDTCs for both of which only a very limited set of microRNAs has been analyzed. FTC: Follicular thyroid carcinoma; PTC: Papillary thyroid carcinoma; PDTC: Poorly differentiated thyroid carcinoma, ATC: Anaplastic thyroid carcinoma. 
reported in at least two individual studies based on comparing signatures between PTCs and NTs (Figure 1). A comparison of PTCs to hyperplastic nodular tissue from formalin fixed paraffin embedded samples further validated the significance of these findings by identifying altered expression of miR-221/-222, -181, -31, and -224 [38]. Upregulation of miR-31 and -224 was also observed by Nikiforova et al. [26]. However, analyses of 40 fine needle aspirate (FNA) specimen and 84 formalin-fixed paraffin-embedded tissues by Chen et al. identified only the upregulation of miR-146b and -222 as potent markers of PTCs [39].

Most interestingly a significant correlation of increased miRNA expression with genetic alterations was observed in PTCs [26]. For instance, miR-221/-222 were more abundant in PTC samples with RAS and BRAF mutations. RAS-mutations moreover correlated with the most severe upregulation of miR-146b. In contrast, RET-mutations were found to be associated with increased expression of miR-155. In vitro analyses using thyroid cancer-derived cells confirmed an 'oncogene connection' for upregulated expression of miR-221 and -181b. The abundance of these microRNAs increased upon overexpression of v-raf, v-ras, RET/PTC1, RET/ PTC3, E1-Abl, E1a-v-raf, middle $\mathrm{T}$ of polyomavirus and $\mathrm{v}$-mos [27]. PTC cell lines harboring RET/PTC1 or BRAF V600E mutations identified additional microRNAs to be severely increased. The most severe upregulation upon BRAF mutation was observed for the miR-200 family (miR-200a, -200b, 200c and -141), whereas RET/ PTC1 rearrangement was correlated with upregulated expression of miR-128a, -128b, -139 and $-200 a$. The most significantly downregulated group of miRNAs in cells with BRAF mutation comprised miR-127, -130a, and -144; with RET/PTC1 rearrangement miR-154*, $-181 \mathrm{a},-302 \mathrm{~b}$ and $-302 \mathrm{c}[40,41]$.

Although there is substantial and consistent data on the upregulation of microRNAs in PTCs, reduced abundance was only reported for a few miRNAs. The three tumor-suppressive miRNA-families miR-26 [31], -30 [38] and let-7 [27] were suggested to be expressed at lower levels in PTCs. Our recent analyses confirmed these observations for the miR-26 and let- 7 families [30]. However, expression of the miR-30 family appeared largely unaffected when compared to NT. In contrast, Schwertheim et al. identified an increased expression of miR-30d, $-30 a,-26 a$ and let-7c in nine analyzed PTCs compared to NTs [36].

In summary, PTCs appear to be well-distinguishable from NT by altered miRNA expression, in particular the upregulation of onco-miRs. However, more comprehensive analyses including FTCs are required to identify miRNAs expressed at distinct levels in these two carcinoma types.

\section{MicroRNA signatures in anaplastic thyroid carcinomas (ATCs)}

The most striking difference between ATCs and all other thyroid carcinomas of follicular origin appears to be a severely decreased expression of various miRNAs (Figure 1) [28,30,36]. Visone et al. observed decreased expression of 20 and elevated abundance of only four miRNAs (miR-222, -198, -let-7f-1, let-7a-2) by comparing ATCs with non-transformed thyroid tissue [28]. The most significant decrease in expression was determined for miR-30d, $-125 b-1 / 2$, and -26a which could be confirmed by Schwertheim et al [36]. In support of these findings, we identified 62 down- and 21 upregulated miRNAs compared to non-transformed thyroid [30]. Strikingly, the decreased miRNAs comprised 12 miRNA-families and 12 clustered miRNA transcription units. The most significant downregulation was observed for tumor suppressive miRNAs of the let-7, miR-26, -30 and -200 families. Notably, the comparison of miRNA signatures between ATCs, PTCs and FTCs suggested that downregulation of the miR-30 and -200 families is sufficient to unambiguously distinguish ATCs from NT as well as FTCs and PTCs. As observed for PTCs, the miR-138 was found to be severely reduced in ATC samples as well as in ATC-derived cell lines [30,31,42,43]. Consistent with our studies and the analyses of ATCderived cells, Nikiforova and colleagues observed a severe upregulation of miR-221/-222 [26,43]. Allthough they examined the expression of 158 microRNAs and identified 57 down- and 47 upregulated in the majority of thyroid tumors they only analyzed the ten most upregulated microRNAs in further detail. Finally, the potent onco-miR-21 was found to be highly expressed in ATCs and was observed to promote thyroid tumor growth in mouse [30,44].

In conclusion, ATCs appear to be well-distinguishable from all other thyroid carcinomas by a severe decrease in the expression of various microRNAs. However, future studies have to reveal if altered miRNA profiles suffice to unambiguously distinguish ATCs from PDTCs.

\section{MicroRNA signatures in poorly differentiated thyroid carcinomas (PDTCs)}

PDTCs are poorly defined and show morphological characteristics of both, differentiated and anaplastic thyroid carcinomas. Aiming to distinguish PDTCs from PTCs and ATCs on the molecular level, Schwertheim et al. investigated the expression of two different sets of microRNAs ('set 1': miRNA-146b, -181b, -21, -221 and -222, all upregulated in PTCs; 'set 2': miRNA-30d, $-125 b,-26 a,-30 a-5 p$ and let7d, all downregulated in ATC). Abundance of these miRNAs was analyzed in comparison to four NTs in 15 PDTCs, nine PTCs and 


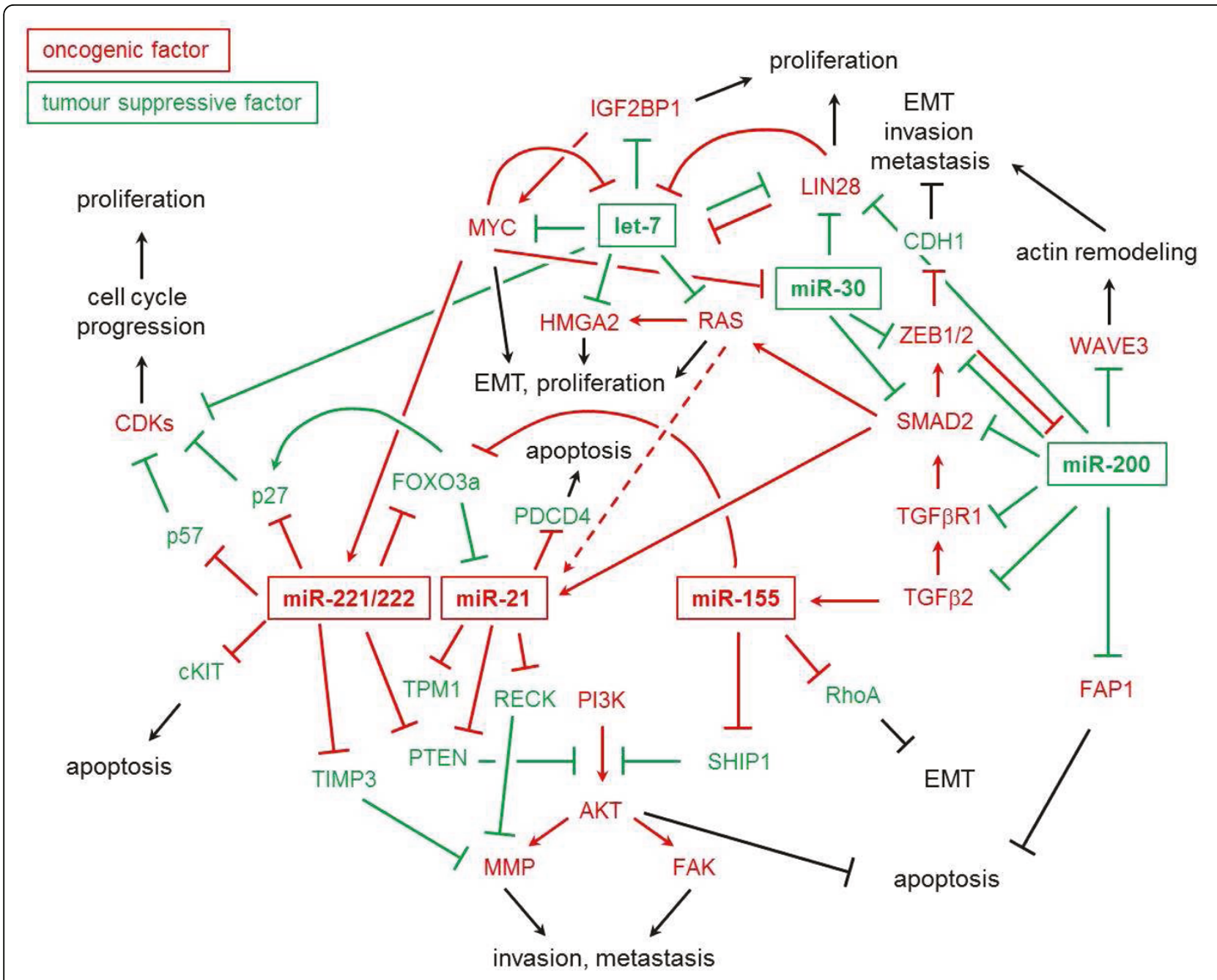

Figure 2 Regulatory networks facilitated by tumor-suppressive and onco-genic microRNAs / proteins in tumor cells. Dashed lines indicate indirect regulation.

nine ATCs [36]. 'Set 1' microRNA expression was slightly increased in PDTCs but did not significantly differ from NTs. Since PTCs and ATCs instead showed a more robust upregulation of these microRNAs, the authors suggested 'set 1' microRNAs as a promising diagnostic tool to distinguish PDTCs from PTCs or ATCs. MicroRNAs of 'set 2' instead appear useful to discriminate PDTCs from PTCs, since they were expressed at low levels in PDTCs and ATCs but significantly upregulated in PTCs. Nikiforova et al. investigated the microRNA expression of four PDTCs but did not aim to distinguish PDTCs from PTCs or ATCs [26]. In contrast to Schwertheim et al., Nikiforova and colleagues found miR-181b, $-221,-222$ and $-146 b$ to be upregulated in all four analyzed PDTCs when compared to NTs [26].

Although preliminary evidence indicates that miRNA profiles could be useful molecular markers to identify
PDTCs, additional and more comprehensive studies are required.

\section{Onco-miRs in Thyroid cancer}

Onco-miRs are typically classified by an upregulation in cancer and the targeting of transcripts encoding effectors antagonizing tumor progression (Figure 2, red). In the following we discuss validated and suggested phenotypic consequences of aberrant onco-miR expression observed in thyroid cancer.

\section{miR-221/-222}

The overexpression of miR-221/-222 is a hallmark of thyroid malignancies [26-28,30,31]. Moreover, upregulation of both miRNAs was also shown in hepatocellular carcinomas (HCC), glioblastoma and gastric cancer [45-47]. Antagonizing the function of miRs-221/222 in PTC-derived cells interfered with cell proliferation and 
growth [27]. In subsequent studies it was demonstrated that both miRNAs negatively regulate expression of the cyclin-dependent kinase (CDK) inhibitor p $27^{\mathrm{Kip} 1}$ [29]. This inhibitory role most likely involves miR-221/222 directed control of FOXO3, a key transcriptional activator of $\mathrm{p} 27^{\mathrm{Kip} 1}[48,49]$. Notably, FOXO3a mRNA was significantly downregulated in PTCs and FOXO3a represses onco-miR-21 in lung cancer cells $[49,50]$. An inhibitory role of both miRNAs was also observed for p5 $7^{\text {Kip2 }}$ expression $[47,51]$. Hence, elevated expression of miR-221/-222 presumably indicates aberrant proliferation and cell growth due to their role in antagonizing cell cycle arrest by targeting crucial cell cycle gatekeepers like CDK-inhibitors. Supporting this view, reduced expression of $\mathrm{p} 27^{\mathrm{Kip} 1}$ was observed in many primary thyroid tumors as well as thyroid carcinomaderived cell lines [52].

The expression of the c-kit tyrosine kinase receptor is suppressed or reduced in most tested FTCs and PTCs [53]. Indicating a role of miR-221/-222 in this regulation, it was demonstrated that both miRNAs target c-kit in melanoma-derived cells [54]. Interestingly, $70 \%$ of cutaneous melanomas are characterized by BRAF mutations which was also shown to be a precaution of miR-221/-222 upregulation in PTC [26]. Various studies showed that miR-221/-222 downregulate expression of the tumor-suppressive phosphatase PTEN leading to an upregulation of PI3K/AKT signaling $[55,56]$. This pathway blocks apoptosis and promotes invasion by modulating focal adhesion kinase (FAK) phosphorylation and matrix metalloprotease (MMP) expression levels [57]. PIK3CA amplifications as well as PTEN mutations were reported for many FTCs, PTCs and ATCs suggesting that AKT signaling is sustained by genomic alterations and modified by post-transcriptional control in thyroid carcinomas $[17,58,59]$. Another pro-apoptotic factor and inhibitor of MMP expression regulated by $\mathrm{miR}-221 /-222$ is TIMP3. Reduced expression of PTEN and TIMP3 facilitated by this miRNA-cluster induces TRAIL (tumor necrosis factor (TNF)-related apoptosis inducing ligand) resistance and upregulation of MMPs [55]. In vivo evidence for the growth promoting role of elevated miR-221/-222 expression was provided by Xenograft studies in nude mice. The constitutive overexpression of this miRNA cluster resulted in an increased gain of Xenograft weight and volume upon subcutaneous injection of tumor-derived cell lines [47]. Together these findings indicate the overexpression of miR-221/-222 as a key event in thyroid tumor progression. Upregulation of both miRNAs presumably promotes uncontrolled growth and could as well modulate the invasive potential of tumor cell.

\section{miR-21}

Upregulated expression of miR-21 is observed in multiple types of cancers, such as breast, liver, brain, prostate and myometrial cancers but also in PTCs and ATCs $[44,60,61]$. Most recently it was shown that oncogenic Ras induces miR-21 expression via activating Raf/MAPK and AKT signaling in rat thyroid cells and in a mouse model of lung tumorigenesis [44]. MiR-21 predominantly acts in an anti-apoptotic manner by interfering with the expression of PTEN and PDCD4 [62-64]. Thus, this miRNA promotes AKT signaling similar to the miR-221/-222 cluster and thereby stimulates its own expression. Elevated AKT signaling and the direct regulation of tropomyosin 1 (TPM1) and maspin (PI5) affects cell morphology, motility and enhances cell invasion $[65,66]$. By the direct targeting of RECK and the indirect effect on TIMP3 expression, upregulation of miR-21 promotes cell migration and invasiveness but also blocks apoptosis [67]. Hence, the overexpression of miR-21 in thyroid cancers is likely to promote uncontrolled growth and potentially upregulated invasiveness of tumor cells.

\section{miR-155}

MiR-155 overexpression was observed in FTCs, PTCs and ATCs [26,31]. In leukemia, miR-155 together with miR-21 stimulates PI3K/AKT signaling by blocking expression of SHIP1, another AKT inhibitory phosphatase $[68,69]$. In addition miR-155 interferes with the expression of RhoA and serves a role in modulating tumor cell invasion as well as epithelial-to-mesenchymal-transition (EMT) [70]. TGF $\beta$ induces miR-155 expression and thereby promotes TGF $\beta$-induced EMT and tight junction dissolution involving the depletion of RhoA. Like miR-221/-222, miR-155 also directly targets FOXO3a [71]. Hence, upregulation of miR-155 in thyroid cancers is presumed to promote cell survival, invasiveness and resistance to chemotherapeutics, as for instance demonstrated in breast cancer cells [71].

\section{Tumor-suppressive miRNAs in thyroid cancer}

In contrast to onco-miRs, tumor-suppressive microRNAs are typically downregulated during tumor progression and target transcripts encoding oncogenic factors. The regulatory role of key tumor-suppressive miRNAs in thyroid cancer is discussed in the following (Figure 2, green).

\section{miR-200}

The miR-200 family (comprising miR-141, -200a, -200b, - 200c and -429) was identified as a potent suppressor of EMT [72-75]. Reduced expression of this miRNAfamily was previously reported for stomach, breast and 
ovarian cancers [76]. Surprisingly, moderately upregulated expression of some miR-200 family members was observed in PTCs and FTCs, whereas a severe downregulation of this microRNA family was found in all ATCs analyzed [30]. This observation supports the view that the miR-200 family serves a key role in preserving an epithelial phenotype or morphology, respectively. Elevated levels of the miR-200 family interfere with the expression of EMT-promoting factors like ZEB1, ZEB2, SNAI2, SMAD2, TGF $\beta$ R1 and TGF $\beta 2$. This antagonizes transcriptional repression of E-cadherin and the miR200 genomic clusters (miR-141/-200c and miR-200a/200b/-429) [30,72-74]. In agreement, severely reduced E-cadherin levels have been described as a common characteristic of primary ATCs as well as ATC-derived cells [30,77]. Moreover, elevated expression of TGF $\beta 2$ was observed in ATC and PDTC compared to FTC and PTC samples [78]. Beyond the antagonistic role in TGF $\beta$-induced EMT, the miR-200 family presumably also modulates actin dynamics by interfering with the expression of WAVE3, an actin cytoskeleton remodeling protein [79]. Taken together, this provides strong evidence that the loss of miR-200 expression presents a hallmark in the progression of thyroid carcinomas culminating in TGF $\beta$-dependent EMT and elevated invasiveness, as observed for ATCs [30]. The loss of miR200 expression is probably potentiated by TGF $\beta$ mediated upregulation of miR-155 expression and enhancement of miR-21-maturation, for both of which a pro-metastatic function was proposed [70,80]. More recently, regulation of LIN28B by miR-200 members was identified in prostate cancer-derived cells [81]. LIN28 is a stem cell factor and a powerful inducer of pluripotency [82]. It also represses maturation of the tumor-suppressive let- 7 family by binding to the loop region of let-7 precursors [83-85]. Additionally, the miR-200 family apparently promotes apoptosis, as demonstrated in colorectal cancer-derived HCT116 cells. In these cells the repression of FAP1 (Fas-associated phosphatase 1 ) by the miR-200 family was correlated with elevated susceptibility to TNF-receptor CD95-dependent apoptosis [86]. In summary, these findings indicate reduced expression of the miR-200 family as a key trigger for dedifferentiation and potentiated aggressiveness observed in ATCs.

\section{let-7}

Downregulation of the let-7 family is observed in all thyroid carcinomas of follicular origin [27,28,30]. Let-7 was initially identified as a factor promoting differentiation in C. elegans and was since then validated as a key regulator of gene expression in various organisms $[87,88]$. The let-7 family is ubiquitously expressed in adult mouse tissue and its reduced expression is considered to be a hallmark in cancer progression [89]. In accord with their tumor-suppressive role, members of the let-7 family target cell cycle regulators and oncogenes like RAS, HMGA1/2, MYC, IGF2BP1 and LIN28 [34,89-93]. Thus it appears likely that the capability to antagonize activating RAS mutations and thus uncontrolled proliferation is severely compromised by reduced levels of the let-7 family. Like activating RAS mutations, the overexpression of MYC is associated with enhanced cell growth and reduced serum dependency in various malignancies [94]. Accordingly, the frequently observed increase of MYC levels in ATCs is likely to correlate with a downregulation of the let-7 family $[78,95,96]$. Notably, MYC is a key regulator of miRNA transcription and negatively controls expression of various tumorsuppressive miRNA clusters including once again the let-7 family but in addition the miR-30, -26, -34 and -29 families $[97,98]$. Another layer of post-transcriptional regulation is provided by the control of MYC mRNA degradation via the RNA binding protein IGF2BP1 (Insulin-like growth factor 2 mRNA binding protein 1) [99]. IGF2BP1 shows an oncofetal expression pattern and becomes de novo synthesized in various cancers [100]. This is in agreement with a reduction of let-7 expression, since members of this miRNA family interfere with IGF2BP1 expression. Thus, MYC-directed repression of the let-7 family is likely to promote the expression of IGF2BP1 that in turn sustains MYC expression [97]. HMGA1 and HMGA2, two other key factors in tumor progression that are controlled by the let-7 family, support the RAS/MEK-facilitated induction of EMT by enhancing SNAIL expression [101-103]. Moreover, HMGA proteins promote cell growth and HMGA1 depletion induces programmed cells death in ATC-derived cells [104]. In conclusion, loss of the let-7 family is likely to be an early event in the progression of thyroid carcinomas. The sever reduction of this tumorsuppressive miRNA family promotes uncontrolled tumor growth and presumably also affects the invasive potential of tumor cells at later stages.

\section{miR-30}

Significantly reduced expression of the miR-30 family was identified in ATCs. However, moderately reduced expression is also observed in FTCs, PTCs and PDTCs, with the exception of miR-30b in FTCs $[28,30]$. The first hint of a potential tumor-suppressive role of this miRNA family was revealed by the identification of UBC9 as a direct target [105]. Downregulation of this E2-conjugating enzyme for sumoylation interferes with cell growth and cancer progression. In bladder cancer, reduced expression of the miR-30 family was associated with upregulation of the tumor marker cytokeratin 7 , although a functional role of this potential regulation 
remains elusive [106]. We identified the miR-30 family as an antagonist of TGF $\beta$-induced EMT and in vitro invasiveness of ATC-derived cells [30]. This role apparently involves the direct targeting of SMAD2 and ZEB2. In agreement, the forced expression of miR-30 family members interfered with in vitro invasiveness of ATCderived cells and correlated with a downregulation of the mesenchymal marker vimentin. However, in contrast to the miR-200 family, expression of the miR-30 family is apparently controlled in a ZEB-independent manner [30]. Intriguingly, the miR-30 family also targets the stem cell factor LIN28, as previously demonstrated for other key tumor-suppressive miRNA families like miR200 and let-7 [107]. Hence, the identification of deregulated expression of the miR-30 family in ATCs identified yet another tumor-suppressive miRNA cluster modulating EMT and invasiveness of tumor cells.

\section{Conclusions}

The comprehensive view of distinct miRNA signatures in thyroid carcinomas of follicular origin provides novel insights in the molecular pathologies of these malignancies. However, knowledge of target mRNAs controlled by deregulated miRNAs in thyroid cancers is still sparse at present. To reveal how altered expression of microRNAs promotes or antagonizes thyroid tumor progression it is thus required to identify novel miRNA targets in future studies.

In thyroid carcinomas the most striking observation is that 'less' aggressive FTCs and PTCs (compared to ATCs) are apparently characterized by an upregulation of 'oncogenic' miRNAs (e.g. miR-221/-222 or miR146b). These miRNAs mainly act in a pro-proliferative and anti-apoptotic manner. In accord with the clonal progression hypothesis, ATCs reveal a severe reduction of tumor-suppressive miRNAs (Figure 1). This decrease presumably promotes dedifferentiation, which morphologically manifests as an epithelial-to-mesenchymal-transition (EMT) driven by reduced expression of the miR200 and -30 families (see Fig. 1 in [30].). Notably, reduction of these miRNA families is likely to provide a valuable diagnostic tool for distinguishing ATCs from FTC or PTCs. Unresolved aspects of immediate diagnostic and potentially therapeutic importance address the question if miRNA signatures are suitable to distinguish FTAs from FTCs. The presented studies seem to be insufficient to define a subset of microRNAs that unambiguously discriminates these thyroid cancers. Thus, it is required to re-evaluate miRNA signatures in thyroid cancers of follicular origin in a comprehensive manner based on pathologically unambiguously classified primary samples. These studies need to be based on the same evaluation method, for instance miRNA- microarrays, to generate data sets allowing an unbiased direct comparison of miRNA signatures.

Despite their potential as diagnostic tools, miRNAs could also provide promising therapeutic targets based on onco-miR inhibition or restoring levels of tumor suppressive miRNAs. The stage for such approaches was set in rodents already in 2005 by demonstrating that the role of miR-16 as well as -122 could be antagonized by the intravenous injection of anti-miRs [108]. Vice versa, the adenoviral delivery of the tumor-suppressive miR-26 was shown to suppress mouse liver tumorigenesis [33]. However, in clinical practice the specificity of miRNA or anti-miR delivery remains an essential limitation due to off-site effects in non-neoplastic organs.

A third strategy could be envisioned on the level of epigenetic silencing of tumor-suppressive miRNAs. In breast and prostate cancer cell lines methylation of the miR-200 cluster was observed and inhibition of methyltransferases released this transcription block [109]. Moreover, epigenetic silencing might explain the observation that complete miRNA transcription units are downregulated in ATCs (Table1 in [30]). Hence, spatially restricted and cluster specific release of epigenetic silencing could provide a valuable tool in the treatment of cancer but as yet such approaches are not available.

In conclusion the here reviewed findings reveal the potency and current limitations of miRNAs in diagnosis, prognosis and potentially therapeutic strategies for the treatment of thyroid cancer. However, substantial additional work will be required to establish miRNAs in clinical practice and reveal the molecular networks via which altered miRNA expression promotes thyroid cancer progression.

\section{Acknowledgement and funding}

This work was supported by DFG funding (GRK1591) to SH. This article has been published as part of Thyroid Research Volume 4 Supplement 1, 2011: New aspects of thyroid hormone synthesis and action. The full contents of the supplement are available online at http://www. thyroidresearchjournal.com/supplements/4/S1

\section{Authors' contribution}

Both authors contributed equally

\section{Competing interests}

The authors declare that they have no competing interests.

Published: 3 August 2011

\section{References}

1. Jemal A, Bray F, Center MM, Ferlay J, Ward E, Forman D: Global cancer statistics. CA Cancer J Clin 61(2):69-90

2. Kondo T, Ezzat S, Asa SL: Pathogenetic mechanisms in thyroid follicularcell neoplasia. Nat Rev Cancer 2006, 6:292-306.

3. Schmid KW: Molecular pathology of thyroid tumors. Pathologe 2010, 31(Suppl 2):229-233.

4. Williams ED: Guest Editorial: Two Proposals Regarding the Terminology of Thyroid Tumors. Int I Surg Pathol 2000, 8:181-183. 
5. DeLellis RA, L RV, Heitz PU, Eng C: World Health Organization Classification of Tumours, Pathology and Genetics of Tumours of Endocrine Organs. 2004, 49-133.

6. Ain KB: Anaplastic thyroid carcinoma: a therapeutic challenge. Semin Surg Oncol 1999, 16:64-69.

7. Pilotti S, Collini P, Mariani L, Placucci M, Bongarzone I, Vigneri P, Cipriani S, Falcetta F, Miceli R, Pierotti MA, Rilke F: Insular carcinoma: a distinct de novo entity among follicular carcinomas of the thyroid gland. Am J Surg Pathol 1997, 21:1466-1473.

8. Williams D: Cancer after nuclear fallout: lessons from the Chernobyl accident. Nat Rev Cancer 2002, 2:543-549.

9. Harach HR, Escalante DA, Day ES: Thyroid cancer and thyroiditis in Salta, Argentina: a 40-yr study in relation to iodine prophylaxis. Endocr Pathol 2002, 13:175-181.

10. Gudmundsson J, Sulem P, Gudbjartsson DF, Jonasson JG, Sigurdsson A, Bergthorsson JT, He H, Blondal T, Geller F, Jakobsdottir M, et al: Common variants on $9 \mathrm{q} 22.33$ and $14 \mathrm{q} 13.3$ predispose to thyroid cancer in European populations. Nat Genet 2009, 41:460-464.

11. Nikiforova MN, Nikiforov YE: Molecular diagnostics and predictors in thyroid cancer. Thyroid 2009, 19:1351-1361.

12. Pallante P, Visone R, Croce CM, Fusco A: Deregulation of microRNA expression in follicular-cell-derived human thyroid carcinomas. Endocr Relat Cancer 2010, 17:F91-104.

13. Wan PT, Garnett MJ, Roe SM, Lee S, Niculescu-Duvaz D, Good VM, Jones CM, Marshall CJ, Springer CJ, Barford D, Marais R: Mechanism of activation of the RAF-ERK signaling pathway by oncogenic mutations of B-RAF. Cell 2004, 116:855-867.

14. Knauf JA, Ma X, Smith EP, Zhang L, Mitsutake N, Liao XH, Refetoff S, Nikiforov YE, Fagin JA: Targeted expression of BRAFV600E in thyroid cells of transgenic mice results in papillary thyroid cancers that undergo dedifferentiation. Cancer Res 2005, 65:4238-4245.

15. Garcia-Rostan G, Camp RL, Herrero A, Carcangiu ML, Rimm DL, Tallini G: Beta-catenin dysregulation in thyroid neoplasms: down-regulation, aberrant nuclear expression, and CTNNB1 exon 3 mutations are markers for aggressive tumor phenotypes and poor prognosis. Am J Pathol 2001, 158:987-996.

16. Miyake N, Maeta H, Horie S, Kitamura Y, Nanba E, Kobayashi K, Terada T: Absence of mutations in the beta-catenin and adenomatous polyposis coli genes in papillary and follicular thyroid carcinomas. Pathol Int 2001, 51:680-685.

17. Paes JE, Ringel MD: Dysregulation of the phosphatidylinositol 3-kinase pathway in thyroid neoplasia. Endocrinol Metab Clin North Am 2008, 37:375-387, viii-ix.

18. Ghildiyal M, Zamore PD: Small silencing RNAs: an expanding universe. Nat Rev Genet 2009, 10:94-108.

19. Fabian MR, Sonenberg N, Filipowicz W: Regulation of mRNA translation and stability by microRNAs. Annu Rev Biochem 2010, 79:351-379.

20. Rigoutsos I: New tricks for animal microRNAS: targeting of amino acid coding regions at conserved and nonconserved sites. Cancer Res 2009, 69:3245-3248.

21. Weber F, Teresi RE, Broelsch CE, Frilling A, Eng C: A limited set of human MicroRNA is deregulated in follicular thyroid carcinoma. J Clin Endocrinol Metab 2006, 91:3584-3591.

22. Schulte KM, Jonas C, Krebs R, Roher HD: Activin A and activin receptors in thyroid cancer. Thyroid 2001, 11:3-14.

23. Boucheix C, Duc GH, Jasmin C, Rubinstein E: Tetraspanins and malignancy. Expert Rev Mol Med 2001, 2001:1-17.

24. Gallagher WM, Greene LM, Ryan MP, Sierra V, Berger A, Laurent-Puig P, Conseiller E: Human fibulin-4: analysis of its biosynthetic processing and mRNA expression in normal and tumour tissues. FEBS Lett 2001, 489:59-66

25. Wlazlinski A, Engers R, Hoffmann MJ, Hader C, Jung V, Muller M, Schulz WA: Downregulation of several fibulin genes in prostate cancer. Prostate 2007, 67:1770-1780.

26. Nikiforova MN, Tseng GC, Steward D, Diorio D, Nikiforov YE: MicroRNA expression profiling of thyroid tumors: biological significance and diagnostic utility. J Clin Endocrinol Metab 2008, 93:1600-1608.

27. Pallante $P$, Visone $R$, Ferracin $M$, Ferraro $A$, Berlingieri MT, Troncone $G$, Chiappetta G, Liu CG, Santoro M, Negrini M, et al: MicroRNA deregulation in human thyroid papillary carcinomas. Endocr Relat Cancer 2006, 13:497-508.
28. Visone $R$, Pallante $P$, Vecchione $A$, Cirombella $R$, Ferracin $M$, Ferraro $A$, Volinia S, Coluzzi S, Leone V, Borbone E, et al: Specific microRNAs are downregulated in human thyroid anaplastic carcinomas. Oncogene 2007, 26:7590-7595.

29. Visone R, Russo L, Pallante P, De Martino I, Ferraro A, Leone V, Borbone E, Petrocca F, Alder H, Croce CM, Fusco A: MicroRNAs (miR)-221 and miR222 , both overexpressed in human thyroid papillary carcinomas, regulate p27Kip1 protein levels and cell cycle. Endocr Relat Cancer 2007, 14:791-798.

30. Braun J, Hoang-Vu C, Dralle H, Huttelmaier S: Downregulation of microRNAs directs the EMT and invasive potential of anaplastic thyroid carcinomas. Oncogene 2010, 29:4237-4244.

31. He H, Jazdzewski K, Li W, Liyanarachchi S, Nagy R, Volinia S, Calin GA, Liu CG, Franssila K, Suster $S$, et al: The role of microRNA genes in papillary thyroid carcinoma. Proc Natl Acad Sci U S A 2005, 102:19075-19080.

32. Ji J, Shi J, Budhu A, Yu Z, Forgues M, Roessler S, Ambs S, Chen Y, Meltzer PS, Croce CM, et al: MicroRNA expression, survival, and response to interferon in liver cancer. N Engl J Med 2009, 361:1437-1447.

33. Kota J, Chivukula RR, O'Donnell KA, Wentzel EA, Montgomery CL, Hwang HW, Chang TC, Vivekanandan P, Torbenson M, Clark KR, et al: Therapeutic microRNA delivery suppresses tumorigenesis in a murine liver cancer model. Cell 2009, 137:1005-1017.

34. Boyerinas B, Park SM, Shomron N, Hedegaard MM, Vinther J, Andersen JS, Feig $C, X u J$, Burge CB, Peter ME: Identification of let-7-regulated oncofetal genes. Cancer Res 2008, 68:2587-2591.

35. Ricarte-Filho JC, Fuziwara CS, Yamashita AS, Rezende E, da-Silva MJ, Kimura ET: Effects of let-7 microRNA on Cell Growth and Differentiation of Papillary Thyroid Cancer. Transl Oncol 2009, 2:236-241.

36. Schwertheim S, Sheu SY, Worm K, Grabellus F, Schmid KW: Analysis of deregulated miRNAs is helpful to distinguish poorly differentiated thyroid carcinoma from papillary thyroid carcinoma. Horm Metab Res 2009, 41:475-481.

37. Sheu SY, Grabellus F, Schwertheim S, Worm K, Broecker-Preuss M, Schmid KW: Differential miRNA expression profiles in variants of papillary thyroid carcinoma and encapsulated follicular thyroid tumours. $\mathrm{Br} J$ Cancer 2010, 102:376-382.

38. Tetzlaff MT, Liu A, Xu X, Master SR, Baldwin DA, Tobias JW, Livolsi VA, Baloch ZW: Differential expression of miRNAs in papillary thyroid carcinoma compared to multinodular goiter using formalin fixed paraffin embedded tissues. Endocr Pathol 2007, 18:163-173.

39. Chen YT, Kitabayashi N, Zhou XK, Fahey TJ 3rd, Scognamiglio T: MicroRNA analysis as a potential diagnostic tool for papillary thyroid carcinoma. Mod Pathol 2008, 21:1139-1146.

40. Cahill S, Smyth P, Denning K, Flavin R, Li J, Potratz A, Guenther SM, Henfrey R, O'Leary JJ, Sheils O: Effect of BRAFV600E mutation on transcription and post-transcriptional regulation in a papillary thyroid carcinoma model. Mol Cancer 2007, 6:21.

41. Cahill S, Smyth P, Finn SP, Denning K, Flavin R, O'Regan EM, Li J, Potratz A, Guenther SM, Henfrey R, et al: Effect of ret/PTC 1 rearrangement on transcription and post-transcriptional regulation in a papillary thyroid carcinoma model. Mol Cancer 2006, 5:70.

42. Takakura S, Mitsutake N, Nakashima M, Namba H, Saenko VA Rogounovitch TI, Nakazawa Y, Hayashi T, Ohtsuru A, Yamashita S: Oncogenic role of miR-17-92 cluster in anaplastic thyroid cancer cells. Cancer Sci 2008, 99:1147-1154.

43. Mitomo S, Maesawa C, Ogasawara S, Iwaya T, Shibazaki M, Yashima-Abo A, Kotani K, Oikawa H, Sakurai E, lzutsu N, et al: Downregulation of miR-138 is associated with overexpression of human telomerase reverse transcriptase protein in human anaplastic thyroid carcinoma cell lines. Cancer Sci 2008, 99:280-286.

44. Frezzetti D, Menna MD, Zoppoli P, Guerra C, Ferraro A, Bello AM, Luca PD, Calabrese C, Fusco A, Ceccarelli M, et al: Upregulation of miR-21 by Ras in vivo and its role in tumor growth. Oncogene 30:275-286.

45. Pineau P, Volinia S, McJunkin K, Marchio A, Battiston C, Terris B, Mazzaferro V, Lowe SW, Croce CM, Dejean A: miR-221 overexpression contributes to liver tumorigenesis. Proc Natl Acad Sci U S A 2010, 107:264-269.

46. Ciafre SA, Galardi S, Mangiola A, Ferracin M, Liu CG, Sabatino G, Negrini M, Maira G, Croce CM, Farace MG: Extensive modulation of a set of microRNAs in primary glioblastoma. Biochem Biophys Res Commun 2005, 334:1351-1358. 
47. Kim YK, Yu J, Han TS, Park SY, Namkoong B, Kim DH, Hur K, Yoo MW, Lee HJ, Yang HK, Kim VN: Functional links between clustered microRNAs: suppression of cell-cycle inhibitors by microRNA clusters in gastric cancer. Nucleic Acids Res 2009, 37:1672-1681.

48. Di Leva G, Gasparini P, Piovan C, Ngankeu A, Garofalo M, Taccioli C, lorio MV, Li M, Volinia S, Alder H, et al: MicroRNA cluster 221-222 and estrogen receptor alpha interactions in breast cancer. J Natl Cancer Inst 2010, 102:706-721.

49. Karger S, Weidinger C, Krause K, Sheu SY, Aigner T, Gimm O, Schmid KW, Dralle H, Fuhrer D: FOXO3a: a novel player in thyroid carcinogenesis? Endocr Relat Cancer 2009, 16:189-199.

50. Wang K, Li PF: Foxo3a regulates apoptosis by negatively targeting miR21. J Biol Chem 2010, 285:16958-16966.

51. Fornari F, Gramantieri L, Ferracin M, Veronese A, Sabbioni S, Calin GA, Grazi GL, Giovannini C, Croce CM, Bolondi L, Negrini M: MiR-221 controls CDKN1C/p57 and CDKN1B/p27 expression in human hepatocellular carcinoma. Oncogene 2008, 27:5651-5661.

52. Baldassarre $G$, Belletti $B$, Bruni $P$, Boccia A, Trapasso F, Pentimalli $F$ Barone MV, Chiappetta G, Vento MT, Spiezia S, et al: Overexpressed cyclin D3 contributes to retaining the growth inhibitor p27 in the cytoplasm of thyroid tumor cells. J Clin Invest 1999, 104:865-874.

53. Natali PG, Berlingieri MT, Nicotra MR, Fusco A, Santoro E, Bigotti A, Vecchio G: Transformation of thyroid epithelium is associated with loss of c-kit receptor. Cancer Res 1995, 55:1787-1791.

54. Igoucheva O, Alexeev V: MicroRNA-dependent regulation of cKit in cutaneous melanoma. Biochem Biophys Res Commun 2009, 379:790-794.

55. Garofalo M, Di Leva G, Romano G, Nuovo G, Suh SS, Ngankeu A, Taccioli C, Pichiorri $F$, Alder $H$, Secchiero $P$, et al: miR-221\&222 regulate TRAIL resistance and enhance tumorigenicity through PTEN and TIMP3 downregulation. Cancer Cell 2009, 16:498-509.

56. Chun-Zhi Z, Lei H, An-Ling Z, Yan-Chao F, Xiao Y, Guang-Xiu W, Zhi-Fan J, Pei-Yu P, Qing-Yu Z, Chun-Sheng K: MicroRNA-221 and microRNA-222 regulate gastric carcinoma cell proliferation and radioresistance by targeting PTEN. BMC Cancer 2010, 10:367.

57. Brader S, Eccles SA: Phosphoinositide 3-kinase signalling pathways in tumor progression, invasion and angiogenesis. Tumori 2004, 90:2-8.

58. Hou P, Ji M, Xing M: Association of PTEN gene methylation with genetic alterations in the phosphatidylinositol 3-kinase/AKT signaling pathway in thyroid tumors. Cancer 2008, 113:2440-2447.

59. Hou P, Liu D, Shan Y, Hu S, Studeman K, Condouris S, Wang Y, Trink A, ElNaggar AK, Tallini G, et al: Genetic alterations and their relationship in the phosphatidylinositol 3-kinase/Akt pathway in thyroid cancer. Clin Cancer Res 2007, 13:1161-1170.

60. Jazbutyte $\mathrm{V}$, Thum T: MicroRNA-21: from cancer to cardiovascular disease. Curr Drug Targets 2010, 11:926-935.

61. Cho WC: OncomiRs: the discovery and progress of microRNAs in cancers. Mol Cancer 2007, 6:60.

62. Meng F, Henson R, Lang M, Wehbe H, Maheshwari S, Mendell JT, Jiang J, Schmittgen TD, Patel T: Involvement of human micro-RNA in growth and response to chemotherapy in human cholangiocarcinoma cell lines. Gastroenterology 2006, 130:2113-2129.

63. Frankel LB, Christoffersen NR, Jacobsen $A$, Lindow $M$, Krogh $A$, Lund $A H$ : Programmed cell death 4 (PDCD4) is an important functional target of the microRNA miR-21 in breast cancer cells. J Biol Chem 2008, 283:1026-1033

64. Lu Z, Liu M, Stribinskis V, Klinge CM, Ramos KS, Colburn NH, Li Y: MicroRNA-21 promotes cell transformation by targeting the programmed cell death 4 gene. Oncogene 2008, 27:4373-4379.

65. Asangani IA, Rasheed SA, Nikolova DA, Leupold JH, Colburn NH, Post S, Allgayer H: MicroRNA-21 (miR-21) post-transcriptionally downregulates tumor suppressor Pdcd4 and stimulates invasion, intravasation and metastasis in colorectal cancer. Oncogene 2008, 27:2128-2136.

66. Zhu S, Wu H, Wu F, Nie D, Sheng S, Mo YY: MicroRNA-21 targets tumor suppressor genes in invasion and metastasis. Cell Res 2008, 18:350-359.

67. Gabriely G, Wurdinger T, Kesari S, Esau CC, Burchard J, Linsley PS, Krichevsky AM: MicroRNA 21 promotes glioma invasion by targeting matrix metalloproteinase regulators. Mol Cell Biol 2008, 28:5369-5380.

68. Yamanaka Y, Tagawa H, Takahashi N, Watanabe A, Guo YM, Iwamoto K, Yamashita J, Saitoh H, Kameoka Y, Shimizu N, et al: Aberrant overexpression of microRNAs activate AKT signaling via down-regulation of tumor suppressors in natural killer-cell lymphoma/leukemia. Blood 2009, 114:3265-3275.

69. Pedersen IM, Otero D, Kao E, Miletic AV, Hother C, Ralfkiaer E, Rickert RC, Gronbaek K, David M: Onco-miR-155 targets SHIP1 to promote TNFalphadependent growth of B cell lymphomas. EMBO Mol Med 2009, 1:288-295.

70. Kong W, Yang H, He L, Zhao JJ, Coppola D, Dalton WS, Cheng JQ: MicroRNA-155 is regulated by the transforming growth factor beta/ Smad pathway and contributes to epithelial cell plasticity by targeting RhoA. Mol Cell Biol 2008, 28:6773-6784.

71. Kong W, He L, Coppola M, Guo J, Esposito NN, Coppola D, Cheng JQ: MicroRNA-155 regulates cell survival, growth, and chemosensitivity by targeting FOXO3a in breast cancer. J Biol Chem 2010, 285:17869-17879.

72. Gregory PA, Bert AG, Paterson EL, Barry SC, Tsykin A, Farshid G, Vadas MA Khew-Goodall Y, Goodall GJ: The miR-200 family and miR-205 regulate epithelial to mesenchymal transition by targeting ZEB1 and SIP1. Nat Cell Biol 2008, 10:593-601.

73. Park SM, Gaur AB, Lengyel E, Peter ME: The miR-200 family determines the epithelial phenotype of cancer cells by targeting the E-cadherin repressors ZEB1 and ZEB2. Genes Dev 2008, 22:894-907.

74. Burk U, Schubert J, Wellner U, Schmalhofer O, Vincan E, Spaderna S, Brabletz T: A reciprocal repression between ZEB1 and members of the miR-200 family promotes EMT and invasion in cancer cells. EMBO Rep 2008, 9:582-589.

75. Korpal M, Lee ES, Hu G, Kang Y: The miR-200 family inhibits epithelialmesenchymal transition and cancer cell migration by direct targeting of E-cadherin transcriptional repressors ZEB1 and ZEB2. J Biol Chem 2008, 283:14910-14914.

76. Brabletz S, Brabletz T: The ZEB/miR-200 feedback loop-a motor of cellular plasticity in development and cancer? EMBO Rep 2010, 11:670-677.

77. Smallridge RC, Marlow LA, Copland JA: Anaplastic thyroid cancer: molecular pathogenesis and emerging therapies. Endocr Relat Cancer 2009, 16:17-44.

78. Montero-Conde C, Martin-Campos JM, Lerma E, Gimenez G, MartinezGuitarte JL, Combalia N, Montaner D, Matias-Guiu X, Dopazo J, de Leiva A, et al: Molecular profiling related to poor prognosis in thyroid carcinoma. Combining gene expression data and biological information. Oncogene 2008, 27:1554-1561.

79. Sossey-Alaoui K, Bialkowska K, Plow EF: The miR200 family of microRNAs regulates WAVE3-dependent cancer cell invasion. J Biol Chem 2009, 284:33019-33029.

80. Davis BN, Hilyard AC, Lagna G, Hata A: SMAD proteins control DROSHAmediated microRNA maturation. Nature 2008, 454:56-61.

81. Kong D, Banerjee S, Ahmad A, Li Y, Wang Z, Sethi S, Sarkar FH: Epithelial to mesenchymal transition is mechanistically linked with stem cell signatures in prostate cancer cells. PLoS One 2010, 5:e12445.

82. Yu J, Vodyanik MA, Smuga-Otto K, Antosiewicz-Bourget J, Frane JL, Tian S, Nie J, Jonsdottir GA, Ruotti V, Stewart R, et al: Induced pluripotent stem cell lines derived from human somatic cells. Science 2007, 318:1917-1920.

83. Newman MA, Thomson JM, Hammond SM: Lin-28 interaction with the Let-7 precursor loop mediates regulated microRNA processing. RNA 2008, 14:1539-1549.

84. Viswanathan SR, Daley GQ, Gregory Rl: Selective blockade of microRNA processing by Lin28. Science 2008, 320:97-100.

85. Rybak A, Fuchs $H$, Smirnova L, Brandt C, Pohl EE, Nitsch R, Wulczyn FG: A feedback loop comprising lin-28 and let-7 controls pre-let-7 maturation during neural stem-cell commitment. Nat Cell Biol 2008, 10:987-993.

86. Schickel R, Park SM, Murmann AE, Peter ME: miR-200c regulates induction of apoptosis through CD95 by targeting FAP-1. Mol Cell 2010, 38:908-915.

87. Reinhart BJ, Slack FJ, Basson M, Pasquinelli AE, Bettinger JC, Rougvie AE, Horvitz HR, Ruvkun G: The 21-nucleotide let-7 RNA regulates developmental timing in Caenorhabditis elegans. Nature 2000, 403:901-906

88. Pasquinelli AE, Reinhart BJ, Slack F, Martindale MQ, Kuroda MI, Maller B, Hayward DC, Ball EE, Degnan B, Muller P, et al: Conservation of the sequence and temporal expression of let-7 heterochronic regulatory RNA. Nature 2000, 408:86-89.

89. Johnson CD, Esquela-Kerscher A, Stefani G, Byrom M, Kelnar K, Ovcharenko D, Wilson M, Wang X, Shelton J, Shingara J, et al: The let-7 microRNA represses cell proliferation pathways in human cells. Cancer Res 2007, 67:7713-7722. 
90. Johnson SM, Grosshans H, Shingara J, Byrom M, Jarvis R, Cheng A, Labourier E, Reinert KL, Brown D, Slack FJ: RAS is regulated by the let-7 microRNA family. Cell 2005, 120:635-647.

91. Sampson VB, Rong NH, Han J, Yang Q, Aris V, Soteropoulos P, Petrelli NJ, Dunn SP, Krueger LJ: MicroRNA let-7a down-regulates MYC and reverts MYC-induced growth in Burkitt lymphoma cells. Cancer Res 2007, 67:9762-9770

92. Lee YS, Dutta A: The tumor suppressor microRNA let-7 represses the HMGA2 oncogene. Genes Dev 2007, 21:1025-1030.

93. Guo Y, Chen Y, Ito H, Watanabe A, Ge X, Kodama T, Aburatani H: Identification and characterization of lin-28 homolog B (LIN28B) in human hepatocellular carcinoma. Gene 2006, 384:51-61.

94. Armelin HA, Armelin MC, Kelly K, Stewart T, Leder P, Cochran BH, Stiles CD: Functional role for c-myc in mitogenic response to platelet-derived growth factor. Nature 1984, 310:655-660.

95. Kurihara T, Ikeda S, Ishizaki Y, Fujimori M, Tokumoto N, Hirata Y, Ozaki S, Okajima M, Sugino K, Asahara T: Immunohistochemical and sequencing analyses of the Wnt signaling components in Japanese anaplastic thyroid cancers. Thyroid 2004, 14:1020-1029.

96. Chang TC, Zeitels LR, Hwang HW, Chivukula RR, Wentzel EA, Dews M, Jung J, Gao P, Dang CV, Beer MA, et al: Lin-28B transactivation is necessary for Myc-mediated let-7 repression and proliferation. Proc Nat Acad Sci U S A 2009, 106:3384-3389.

97. Chang TC, Yu D, Lee YS, Wentzel EA, Arking DE, West KM, Dang CV, Thomas-Tikhonenko A, Mendell JT: Widespread microRNA repression by Myc contributes to tumorigenesis. Nat Genet 2008, 40:43-50.

98. Mott JL, Kurita S, Cazanave SC, Bronk SF, Werneburg NW, FernandezZapico ME: Transcriptional suppression of mir-29b-1/mir-29a promoter by c-Myc, hedgehog, and NF-kappaB. J Cell Biochem 2010, 110:1155-1164.

99. Prokipcak RD, Herrick DJ, Ross J: Purification and properties of a protein that binds to the $\mathrm{C}$-terminal coding region of human c-myc mRNA. J Biol Chem 1994, 269:9261-9269.

100. Yisraeli JK: VICKZ proteins: a multi-talented family of regulatory RNAbinding proteins. Biol Cell 2005, 97:87-96.

101. Watanabe S, Ueda Y, Akaboshi S, Hino Y, Sekita Y, Nakao M: HMGA2 maintains oncogenic RAS-induced epithelial-mesenchymal transition in human pancreatic cancer cells. Am J Pathol 2009, 174:854-868.

102. Thuault S, Tan EJ, Peinado H, Cano A, Heldin CH, Moustakas A: HMGA2 and Smads co-regulate SNAIL1 expression during induction of epithelial-tomesenchymal transition. J Biol Chem 2008, 283:33437-33446.

103. Selbach M, Schwanhausser B, Thierfelder N, Fang Z, Khanin R, Rajewsky N: Widespread changes in protein synthesis induced by microRNAs. Nature 2008, 455:58-63.

104. Scala S, Portella G, Fedele M, Chiappetta G, Fusco A: Adenovirus-mediated suppression of $\mathrm{HMGI}(\mathrm{Y})$ protein synthesis as potential therapy of human malignant neoplasias. Proc Natl Acad Sci U S A 2000, 97:4256-4261.

105. Wu F, Zhu S, Ding Y, Beck WT, Mo YY: MicroRNA-mediated regulation of Ubc9 expression in cancer cells. Clin Cancer Res 2009, 15:1550-1557.

106. Ichimi T, Enokida H, Okuno Y, Kunimoto R, Chiyomaru T, Kawamoto K, Kawahara K, Toki K, Kawakami K, Nishiyama K, et al: Identification of novel microRNA targets based on microRNA signatures in bladder cancer. Int $J$ Cancer 2009, 125:345--352.

107. Zhong X, Li N, Liang S, Huang Q, Coukos G, Zhang L: Identification of microRNAs regulating reprogramming factor LIN28 in embryonic stem cells and cancer cells. J Biol Chem 2010.

108. Krutzfeldt J, Rajewsky N, Braich R, Rajeev KG, Tuschl T, Manoharan M, Stoffel M: Silencing of microRNAs in vivo with 'antagomirs'. Nature 2005 438:685-689.

109. Vrba L, Jensen TJ, Garbe JC, Heimark RL, Cress AE, Dickinson S, Stampfer MR, Futscher BW: Role for DNA methylation in the regulation of miR-200c and miR-141 expression in normal and cancer cells. PLoS One 2010, 5:e8697.

doi:10.1186/1756-6614-4-S1-S1

Cite this article as: Braun and Hüttelmaier: Pathogenic mechanisms of deregulated microRNA expression in thyroid carcinomas of follicular origin. Thyroid Research 2011 4(Suppl 1):S1.

\section{Submit your next manuscript to BioMed Central and take full advantage of:}

- Convenient online submission

- Thorough peer review

- No space constraints or color figure charges

- Immediate publication on acceptance

- Inclusion in PubMed, CAS, Scopus and Google Scholar

- Research which is freely available for redistribution 